\title{
Strengthening partnerships: The involvement of health care providers in the evaluation of authentic assessment within midwifery undergraduate education
}

\begin{abstract}
Collaborative partnerships between health care providers and academics are essential in the provision of quality undergraduate midwifery programs. While health care providers often contribute to clinical assessment and teaching in midwifery programs, they are rarely involved in assessment design and evaluation.
\end{abstract}

This paper describes the evaluation of an assessment task designed to develop critical thinking skills in final year undergraduate midwifery students. Health care providers' involvement sought to confirm the authenticity and validity of the assessment task and facilitate further engagement.

A mixed method descriptive study design was used. After reviewing a sample of student work, health care providers completed a 20 item survey and participated in a focus group. Survey items were based on the domains of Educational Acceptability, Educational Impact and Preparation for Practice. Participants gave high scores for each domain and commented positively on the innovative nature of the assessment, students' ability to undertake in-depth analysis of complex cases, and development of student's critical thinking skills. Participants also reported greater confidence in students' competence and the program. 
Involving health care providers in evaluation of an assessment task validated the assessment, contributed to clinicians' perceptions of student credibility, and fostered strong links between the program and industry.

Key Words: midwifery education, critical thinking, university-industry partnerships, course evaluation, root-cause analysis

\section{INTRODUCTION}

The use of authentic assessment to promote deep learning in higher education has been increasingly encouraged over the last decade (Biggs and Tang, 2007). Likewise, the development and maintenance of collaborative partnerships between health care providers and academics are essential in the provision of quality teaching and learning experiences for undergraduate health care students (Dignam et al., 2012); especially those leading to registration such as midwifery. Although health care providers often contribute to clinical assessment and teaching in midwifery programs, they are rarely involved in the design and evaluation of specific assessment items.

As part of an ongoing program of scholarship designed to support excellence in teaching and learning we sought input from our health service partners to evaluate the extent to which an assessment task for final year student midwives was appropriate for measuring critical thinking capacity; risk assessment abilities, complex decisionmaking, and teamwork. This paper describes the evaluation of this curriculum initiative 
undertaken within a Bachelor of Midwifery program at one publically-funded, research intensive Australian university. Both students and health care providers were involved in the evaluation. Students' evaluation responses have been published previously (Carter et al., 2014). This paper reports on the findings from health service partners who evaluated the assessment process. The following critical elements will be discussed in this paper: the significance of health service engagement; development of an authentic assessment task; involvement of health service partners, and clinicians' evaluation of this strategy.

\section{Significance of health service engagement}

The concept of 'industry' or health service provider engagement is critical to the contemporaneous nature of midwifery programs but is often neglected. While policy directives and reports in Australia and internationally advocate for engagement of health care providers in educational programs for health professionals (Clare, 2003; Nursing and Midwifery Council, 2010; ANMAC, 2010), a dearth of literature exists evaluating strategies to achieve this. Industry engagement is both under-researched and politically sensitive (Payne, 2008) with very little formal analysis of curriculum activities involving industry. This may be because efforts to engage industry with curriculum are highly variable, often time consuming, and rarely evaluated (Woodley and Johnson 2010). The lack of collaboration and negative interactions may be

underpinned by conflicting philosophies of clinicians and academics (Lange and Kennedy, 2006). The ideals of the tertiary sector and reality in healthcare settings, may contribute to inconsistencies in information sharing, varying levels of support of students during clinical placements, and mutual dissatisfaction (Greenwood, 2000; Newton el al. 2009). However, authentic engagement that involves frequent contact 
between academic and health care providers can enhance collaboration by increasing trust and mutual respect (Chalmers et al., 2001; Dignam, et al., 2012; Spouse, 2002). While health care providers often contribute to clinical teaching and clinical assessment in both nursing and midwifery, they are rarely involved in assessment design and evaluation. In undergraduate midwifery programs in Australia, health service engagement is further hindered by the fragmented model of clinical placement where universities compete for limited places and maternity units/hospitals are often facilitating placement for several universities simultaneously.

Engagement of health care providers in the development of curriculum and evaluation of assessment tasks can be a useful strategy to further develop collaborative partnerships, and build clinicians' confidence in graduates' knowledge and analytic abilities. Health service involvement can promote allegiance and confidence in the program, further engaging clinicians in student learning (Chalmers et al., 2001; Spouse, 2002). From commencement of the Bachelor of Midwifery program at Griffith University in 2010, active and meaningful ways to develop partnerships with health service colleagues were established. Health service partners were consulted and engaged in the design and development of the curriculum. As the three year program was implemented other collaborative engagement activities were devised and clinicians were invited to be members of the program advisory group. University lecturers maintained a regular physical presence at partner hospitals facilitating student placements, and academics were appointed onto hospital reference groups and decision-making bodies. The curriculum initiative presented in this paper sought to further develop health service engagement and foster collaborative relationships in learning and teaching by requesting health service partners to evaluate the effectiveness of a third year assessment task. This approach aimed to engage health 
service partners in the assessment process and showcase the standard of student work.

\section{Development of an authentic assessment task}

Assessment is often the most influential force for learning (Biggs and Tang, 2007). Some time ago Elton and Johnston (2002) estimated that students spend less than 10 per cent of their time on academic work that is non-assessed. The impact of assessment on student learning and use of assessment items that promote deeper learning in higher education has been increasingly recognised as essential to quality educational outcomes (Biggs and Tang, 2007).

As the assessment task occurred in the final capstone course of the degree, the academic team was cognisant of the need to design an authentic assessment task that prepared students for autonomous midwifery practice. An authentic assessment task replicates real world challenges, requires students to demonstrate the same combination of knowledge, skills and attitudes needed in the workplace, and enables them to become proficient in situations they will encounter as practitioners (Mueller, 2005; Tiwari, et al., 2005). Authentic assessment has the potential to stimulate deeper learning, enabling students to develop professionally and increases their motivation because all learning is perceived to be relevant to their future professional practice.

In order to prepare for contemporary, autonomous midwifery practice, students require well developed critical thinking skills, an ability to work in teams, and sound clinical decision making abilities in uncertain and unpredictable circumstances (Homer et al., 2009). The ability to practice safely is one of the most important attributes of a competent midwife (Butler et al., 2008). In order for student midwives to become safe 
practitioners, they need to understand and have the opportunity to participate in risk management and quality improvement activities. This preparation requires both knowledge-based and performance outcomes to be assessed at course level to ensure that graduating midwives are able to effectively implement continuous quality improvement strategies and communicate concerns to demonstrate safe practice. One key element of this preparation deals with widely-adopted formal approaches to assessing or predicting potential medical errors: root cause analysis (RCA). A RCA is a structured approach to investigating sentinel events with a focus on identifying the source of the problem and formulating recommendations that will prevent the problem reoccurring (Connelly, 2012). Unfortunately, "after-the-fact" analyses of medical errors is often focused on individual accountability and reprimand which is an ineffective method of enhancing safe practice and seldom helps to improve the overall quality of care. In contrast a RCA focusses on identifying system and process factors that contributed to errors (Pearson, 2005).

In an effort to transform midwifery education and improve health care quality, the Australian Nursing and Midwifery Council (ANMAC) Accreditation Guidelines (2010) refer to competencies, systems-based practice, and practice-based learning and improvement. These approaches call for a shift from narrow, discipline-specific views of care practices to an integrated model that enhances organisational excellence. There is an expectation that education programs will teach students how to systematically analyse practice with quality improvement methods, implement change strategies with the goal of practice improvement, work in teams to enhance safe practice, and participate in the identification of "system" errors with the goal of 
implementing "system" solutions. There is limited research on novel methods to empower graduating midwifery students to meaningfully engage and improve quality.

The use of interactive activities to develop midwifery students' decision making skills in complex situations is a key strategy to build competent and confident midwives (Skirton et al., 2012). While clinical simulation using an OSCE (Objective Structured Clinical Examination) role play can test knowledge and abilities in a practical way simulation activities are limited in developing critical thinking in clinical situations where interpretation of multiple data sources is required (Mitchell et al., 2009). The use of a simulated RCA with undergraduate nursing students has been reported to reduce the likelihood of clinical errors (Lamberton and Mahlmeister, 2010). This type of assessment has not been examined in midwifery education and its' ability to develop critical thinking has not been explored.

The assessment item evaluated here required students to undertake a root cause analysis of critical scenarios in small groups (3-4 students per group). The scenarios were taken from real life coroners' cases involving either maternal or neonatal mortality which were sourced via the internet from Australia, New Zealand and the United Kingdom. Students identified issues within their case, drew on theoretical and clinical knowledge, identified potential system and process errors and made recommendations for practice (Carter et al., 2014). The root cause analysis assessment item allowed time for information gathering, group discussion and reflection within a safe framework. The assessment item enabled students' to consider the internal and external influences on practice both at an individual level and an institutional level. This activity also tested the students' ability to work in a group and demonstrate understanding of the value of good communication and interdisciplinary 
collaboration in practice. Student groups presented their findings and recommendations to colleagues via an online real time classroom.

\section{METHOD}

A mixed method descriptive design was used. The health service partners were five senior midwifery clinicians/managers/educators from maternity services where students were undertaking clinical placement.

\section{$\underline{\text { Measure }}$}

The concepts inherent in the utility framework were used to guide the development of an evaluation survey (van der Vleuten, 1996). According to van der Vleuten (1996) relevant factors include reliability, validity, educational impact, acceptability, and cost effectiveness. Within this framework, the value of an assessment format considers aspects inherently linked to the curriculum. Developing items around the concepts educational acceptability, impact and preparation for practice were considered most relevant to the evaluation process by expert midwifery clinicians.

Twenty items were developed and grouped under the domain headings of Educational Accessibility $(n=5)$, Educational Impact $(n=7)$ and Preparation for Practice $(n=8)$ (Table 2). Item responses were on a 5-point Likert scale of $1=$ strongly disagree to 5 = strongly agree. Before use, the survey tool was reviewed by an independent expert panel $(n=5)$ consisting of midwifery educators, clinicians, managers and government advisors. Detail related to the survey development process was published earlier (Carter et al., 2014). 
In addition, the health service partners were asked to comment on the positive features of the assessment item; how the assessment item could be improved; and what they considered the most important student learning outcomes would be from this assessment item.

Table 1: Health Service Partner characteristics

\begin{tabular}{|c|l|}
\hline Age, years & $\mathbf{n}(\%)$ \\
\hline $36-45$ & $3(60.0)$ \\
\hline $46-55$ & $2(40.0)$ \\
\hline Education & \\
\hline Certificate & $1(20.0)$ \\
\hline Bachelors & $1(20.0)$ \\
\hline Masters & $2(40.0)$ \\
\hline Doctorate & $1(20.0)$ \\
\hline $\begin{array}{l}\text { Years Registered as } \\
\text { Midwife }\end{array}$ & \\
\hline $5-10$ & $1(20.0)$ \\
\hline $16-20$ & $1(20.0)$ \\
\hline$>20$ & $3(60.0)$ \\
\hline Position & $2(40.0)$ \\
\hline Midwifery Unit Manager & $2(40.0)$ \\
\hline Midwifery Unit Director & $1(20.0)$ \\
\hline Clinical Facilitator & \\
\hline
\end{tabular}

Table 2: Health Service Partner survey responses

\begin{tabular}{|c|c|}
\hline $\begin{array}{l}\text { Utility index survey item } \\
\text { Domain - Educational Acceptability }\end{array}$ & $\begin{array}{c}\text { Mean } \\
\text { (standard deviation) }\end{array}$ \\
\hline $\begin{array}{l}\text { 1. This assessment item engaged the students } \\
\text { in learning }\end{array}$ & $5.0(00)$ \\
\hline $\begin{array}{l}\text { 2. This assessment item would be interesting } \\
\text { for students to research and prepare }\end{array}$ & $4.75(.50)$ \\
\hline $\begin{array}{l}\text { 3. The critical incidents provided are similar to } \\
\text { those faced in the clinical environment }\end{array}$ & $4.80(.48)$ \\
\hline $\begin{array}{l}\text { 4. This is an appropriate assessment for final } \\
\text { year Bachelor of Midwifery students }\end{array}$ & $4.80(.48)$ \\
\hline $\begin{array}{l}\text { 5. I would recommend this assessment item } \\
\text { continue within this course }\end{array}$ & $5.0(0)$ \\
\hline \multicolumn{2}{|l|}{ Domain - Educational Impact } \\
\hline $\begin{array}{l}\text { 1. This assessment item enhances student } \\
\text { learning }\end{array}$ & $4.80(.447)$ \\
\hline $\begin{array}{l}\text { 2. This assessment item encourages students' } \\
\text { critical thinking skills }\end{array}$ & $4.60(.548)$ \\
\hline $\begin{array}{l}\text { 3. This assessment item develops a students' } \\
\text { decision making skills }\end{array}$ & $4.40(.548)$ \\
\hline $\begin{array}{l}\text { 4. This assessment item enhances students' } \\
\text { ability to assess complex needs }\end{array}$ & $4.50(. .577)$ \\
\hline
\end{tabular}




\begin{tabular}{|c|c|}
\hline $\begin{array}{l}\text { 5. This assessment item challenges student's } \\
\text { thinking }\end{array}$ & $4.60(.548)$ \\
\hline $\begin{array}{l}\text { 6. This assessment item encouraged students } \\
\text { to examine the whole clinical situation rather } \\
\text { than the tasks at hand }\end{array}$ & $4.60(.548)$ \\
\hline $\begin{array}{l}\text { 7. This assessment item measures the } \\
\text { relevant course objectives }\end{array}$ & $4.60(.548)$ \\
\hline \multicolumn{2}{|l|}{ Domain - Preparation for Practice } \\
\hline $\begin{array}{l}\text { 1. Students will be more confident and able to } \\
\text { make appropriate clinical decisions in } \\
\text { complex situations after successfully } \\
\text { completing this assessment }\end{array}$ & $4.40(.548)$ \\
\hline $\begin{array}{l}\text { 2. Students will gain an enhanced } \\
\text { understanding of midwives' accountability } \\
\text { after successful completion of this } \\
\text { assessment }\end{array}$ & $4.60(.548)$ \\
\hline $\begin{array}{l}\text { 3. This assessment item develops students' } \\
\text { appreciation of the value and extent of other } \\
\text { roles within the wider health care team }\end{array}$ & $4.80(.447)$ \\
\hline $\begin{array}{l}\text { 4. This assessment item promotes the } \\
\text { development of skills in collaborative } \\
\text { practice }\end{array}$ & $4.40(.894)$ \\
\hline $\begin{array}{l}\text { 5. Students will be more aware of the causes } \\
\text { of critical incidents following the completion } \\
\text { of this assessment item }\end{array}$ & $4.60(.548)$ \\
\hline $\begin{array}{l}\text { 6. Students are less likely to make clinical } \\
\text { errors following completion of this } \\
\text { assessment item }\end{array}$ & $3.60(.548)$ \\
\hline $\begin{array}{l}\text { 7. Teaching students to use risk management } \\
\text { and clinical governance principles in this } \\
\text { way assists them in meeting the ANMC } \\
\text { Competencies }\end{array}$ & $4.60(.548)$ \\
\hline $\begin{array}{l}\text { 8. This assessment item assists prepare } \\
\text { student midwives for midwifery practice }\end{array}$ & $4.20(.447)$ \\
\hline
\end{tabular}

\section{Procedure}

Health service providers from each of our partner hospitals were members of the Griffith Midwifery Advisory Group. These midwives have played an integral part in the initial development and ongoing monitoring and evaluation of the Bachelor of Midwifery program and welcomed the opportunity to take part in this study. An email request was sent informing them of the background and significance of the study and inviting them to take part. Participants had an opportunity to question the research team prior to agreeing to take part. A total of nine health service partners were invited 
to participate in the study and five were able to attend. Reason for non-attendance was competing work requirements.

On arrival to the session participants signed a consent form indicating their willingness to participate and abide by the principles of confidentiality related to viewing student presentations. Health service partners were provided with the associated course profile and learning outcomes, assessment instructions and description, and marking rubric. A group discussion occurred regarding the purpose and conduct of the assessment item. Two student presentations were then viewed. After viewing the presentations, the health service partners were asked to complete the 20 -item expert midwifery clinician survey tool. After completing the survey, a semi-structured focus group was conducted by the researcher in order to elicit views about the assessment item and areas for improvement. Ethical approval was obtained from the University Human Research Ethics Committee.

\section{Approach to analysis}

Survey responses were entered into SPSS Statistics Version 21, IBM. Descriptive statistics using mean scores and standard deviations were calculated for each domain as well as responses to each item.

Latent content analysis was applied to the qualitative data (Graneheim and Lundaman, 2004) gathered from survey and the focus group. Responses were typed up and formatted into a Word document table. Hard copies were read and notes made and shared with the team. Similar significant statements or phrases were identified and clustered together under positive aspects, improvements and perceptions of the most 
important learning outcomes. Each participant was allocated a number for coding purposes only.

\section{RESULTS}

\section{Participant characteristics}

Health service participants $(n=5)$ had varying qualifications ranging from certificate to doctorate. They all had over 5 years clinical midwifery experience with three practising for more than 20 years. Characteristics of participants are outlined in Table 1.

\section{Survey results}

The mean scores for each domain were high for Educational Acceptability (mean= 4.87, $\mathrm{SD}=.19$ ), Educational Impact (mean $=4.58, \mathrm{SD}=.39$ ) and Preparation for Practice $($ mean $=4.4, \mathrm{SD}=.38)$ as shown in Table 2. Overall health services partner responses to each item were positive with no item mean less than 3.60.

Highest scores were obtained in the domain of Educational Acceptability with no mean rating below 4.75 . Health service partners unanimously agreed that the assessment item would engage students in learning $($ mean $=5)$, and considered that the critical incident case materials reflected those faced in the clinical environment (mean $=4.8$ ). This validates the assessment authenticity and 'real world' application. Health service partners unanimously recommended that this assessment be retained in the course $($ mean $=5)$.

Items in the domain of Educational Impact were also rated highly. Health service partners consistently agreed that the assessment items developed student's critical thinking skills (mean $=4.6$ ), and decision making skills (mean $=4.4$ ), challenged their 
thinking (mean 4.6) and encouraged them to examine the whole clinical situation rather than the tasks at hand (mean $=4.6)$. Health service partners also acknowledged that the assessment process measured the relevant course objectives (mean $=4.6$ ).

Responses to items in the domain of Preparation for Practice were positive but ranked slightly less favourably than responses on other subscales. Expert midwifery clinicians perceived that undertaking the root cause analysis developed students' appreciation of the value and extent of other roles within the wider health care team (mean $=4.8$ ) and promoted the development of skills in collaborative practice (mean $=4.4)$. They also considered the assessment item enhanced the student's understanding of the midwives' accountability (mean $=4.6$ ) and decreased their likelihood of making clinical errors $($ mean $=4.0)$. Health service partners reported student's would be more aware of the causes of critical incidents (mean $=4.6$ ) and prepare students for practice (mean $=4.2$ ), but reported less agreement that following completion of this assessment item students would be less likely to make clinical errors (mean $=3.6$ ).

\section{Qualitative survey responses and focus group discussions}

All participants found the root cause analysis to be a useful assessment item. Participants clearly perceived that the development of critical thinking was fostered in this assessment task. For example, P2 stated, "Overall consolidation of knowledge was evident in this assessment. Development of critical thinking is an essential skill required to be an excellent midwifery practitioner, this assessment contributes to that skill set". Likewise P5 commented, "It gives students an excellent overview of how important it is to approach any situation in a critical way". 
Another positive aspect of the assessment item related to clinical governance and risk management. P4 summed this up well when she wrote in point form;

Real scenarios are relevant to practice/ best practice;

A risk management framework was used to identify issues;

Students are informed about clinical guidelines and contemporary practice/ evidence-based practice; and

No blame approach and systems analysis are highlighted.

A significant intent of the RCA assessment item was to teach/ consolidate these issues, so it was gratifying to have these aspects affirmed by health service partners.

Health service partners were also asked for suggestions to improve the assessment process. Four out of five midwives felt the process was not in need of improvement. The fifth suggested a restructure to the order in which students' presented their recommended findings from their RCA.

When asked to identify the most important learning outcomes from the assessment item our health service partners firstly noted 'critical thinking' and 'objectivity'. They considered these as being significant in midwifery practice. P1 stated that the assessment led to "awareness and conscious recognition of all the factors which contribute to governance for safety"; with P4 saying the assessment drew students' attention to "National Health and Quality Safety Standards, importance of education and CPD, [and] accountability and responsibility of all health professionals". 
An awareness of multifaceted approaches to care/ communication was also identified as an important learning outcome. P5 identified that students could learn from this assessment in that, "appropriate communication is important" and "Collaboration with all the team" is essential.

In the focus group discussions health service partners commented on the time consuming nature of this assessment task and expressed some concern related to student workload. Considering the time expended on this assessment task several midwives commented they would like to see the students' work more widely communicated. P4 suggested to "use these presentations in clinical settings/ share with midwives".

Although health service partners were only asked to evaluate the assessment item and not individual student performance, comments on students' work were made during the focus group. Several clinicians commented favourably on the high level of student performance, adding that many registered midwives could not undertake such a sophisticated root cause analysis. As P1 said "There are many practising midwives that would benefit from this [undertaking this assessment item]". The process of viewing students' presentations as part of this evaluation further consolidated health service partners' confidence in students' abilities and the curriculum as a whole. This project was undertaken at the end of semester with the program's first group of graduating students. This may have enhanced employment opportunities for graduates, as following viewing student presentations health service partners expressed interest in employing students from this program. P2 articulated her enthusiasm, "Well done. I am so excited about the introduction into the workforce of these midwives". 


\section{DISCUSSION}

This descriptive study described a process of health service providers' engagement in the evaluation of a novel assessment task designed to develop students' cognitive competence in preparation for autonomous midwifery practice. The validity of the assessment process was endorsed with "educational acceptability" and "educational impact" being rated highly, but with slightly less agreement on the effect of the assessment process to "prepare students for practice". The lower scoring related to preparation for practice could be due to health service partners not being adequately informed about the scope of assessment that students complete throughout the entire degree program. This root cause analysis assessment process, although innovative and authentic, is only one item within a scaffolded program of assessment preparing midwifery students for practice. Similar evaluation of assessment items within the program would be beneficial to further validate these items and promote further health service engagement.

Health service partners also commented favourably on the development of students' understanding of various roles within the multidisciplinary team and collaborative skills. Other aspects highlighted during focus group discussions included improved student awareness about the importance of communication in every adverse situation. Health service partners also endorsed the concept of using group work for this assessment as a strategy to develop collaboration and conflict resolution skills. Teamwork skills are not only an effective vehicle to enhance learning but are considered a useful transferable skill highly valued by employers (Corby, 2013).

Concerns raised in the focus groups were primarily about the time consuming nature of the task. Health service partners commented on the multi-faceted nature of the 
project, complexities of each case being analysed, and research required to complete the analysis. Students made similar comments (Carter et al., 2014), however in a 6 month follow-up of graduates, anecdotal evidence suggests that students reported the RCA was one of the most valuable assessment activities in the degree program to prepare them for safe practice.

Although our findings are positive, they need to be considered in light of limitations of the study. Generalizability of results is limited by the use of a single program and small sample. However, there was a high level of agreement amongst respondents, lending some confidence to the conclusions. The sample size also limited the extent of statistical analysis. Furthermore, the survey tool needs to be examined with a larger sample and tested for reliability.

\section{Implications for teaching practice and research}

Although the results indicated a high level of validation and overall satisfaction with the assessment process from health service partners, some changes were highlighted. While the scores were positive in the domain of Preparation for Practice,

they ranked slightly less favourably than responses on other subscales. A detailed explanation of the curriculum assessment map and the scaffolding of its complexity and development of skills and knowledge will be provided in the future to health service partners. This would place the RCA assessment item in context and further promote how this assessment item builds on prior knowledge and skills promoting competence, capability and confidence.

Health service partners identified that the assessment task was time consuming, requiring considerable research. The multifaceted nature of the assessment that involved research, group work, write up and preparation for the group presentation 
may have contributed to this perception. This has subsequently been addressed by providing students with examples of root cause analysis frameworks to use. Furthermore several improvements to the instructions have now been made to provide explicit details about the nature of the assessment, and some useful tips on how to prioritise work and manage time. The marking rubric has been modified with more explicit marking criteria and exemplars are now provided.

The importance of team work was further highlighted by heath service partners. Students often dislike group work assessments, and academic staff may have limited experience in teaching group work skills or assessing the process of teamwork as opposed to its outputs (Corby, 2013). Our experience also suggests that students found group work challenging. When difficulties arise while working in groups, students are often unable to pinpoint how to modify their behaviour to improve the situation. The principles of group work have now been introduced early in the program and experiential activities are planned so that students are better prepared to work with others, have good process problem-solving skills and improved negotiation and conflict resolution skills.

\section{CONCLUSIONS}

Analysing complex clinical cases to determine a root cause was validated by health service providers as an authentic assessment task that represented 'real world' midwifery problems. Health service providers partners perceived this assessment would develop student's critical thinking, decision making and teamwork skills. Coroners' cases can provide a high level of clinical information that is unpredictable, ambiguous and complex, and hence well suited to develop students higher ordered thinking, preparing them for the uncertainties of midwifery practice. The process of 
involving health service providers in evaluation of this assessment contributed to their confidence in student's credibility and further fostered strong collaborative partnerships. 


\section{References}

Australian Nursing and Midwifery Council, 2010. Midwives: standards and criteria for the accreditation of nursing and midwifery courses leading to registration, enrolment, endorsement and authorisation in Australia (Canberra).

Biggs, J., Tang, C., 2007. Teaching for Quality Learning at University 3rd ed. Open University Press, Maidenhead, GBR.

Butler, M.M., Fraser, D.M., Murphy, R.J.L., 2008. What are the essential competencies required of a midwife at the point of registration? Midwifery 24 (3), 260-269.

Carter, A.G., Sidebotham, M., Creedy, D.K., Fenwick. J., Gamble, J., 2014. Using root cause analysis to promote critical thinking in final year Bachelor of Midwifery students. Nurse Education Today 34 (6), 1018-23. doi:10.1016/j.nedt.2013.10.020

Chalmers, H., Swallow, V. M., Miller, J., 2001. Accredited work-based learning: an approach for collaboration between higher education and practice, Nurse Education Today (21) 5, 597-606.

Clare, J., 2003. Evaluating clinical learning environments: Creating education-practice partnerships and clinical education benchmarks for nursing, AUTC Phase Two Final Report, Flinders University, Adelaide, Australia.

Connelly, L.M., 2012. Root cause analysis. Medsurg Nursing 21 (5), 316, 313.

Corby, D., 2013. Improving services through co-operative learning. Learning Disability Practice 16 (2), 28-30.

Dignam, D., Duffield, C., Stasa, H., Gray, J., Jackson, D. Daly, J., 2012.

Management and leadership in nursing: an Australian perspective. Journal of Nursing Management, 20, 65-71.

Elton, L., Johnston, B., 2002. Assessment in Universities: a critical review of research Learning and Teaching Support Network (LTSN) Generic Centre: York.

Greenwood, J. 2000., Critique of the graduate nurse: An international perspective. Nurse Education Today. 20 (1),17-29.

Graneheim, U.H., Lundman, B., 2004. Qualitative content analysis in nursing research: concepts, procedures and measures to achieve trustworthiness. Nurse Education Today, 24, 105-112.

Homer, C.S., Passant, L., Brodie, P.M., Kildea, S., Leap, N., Pincombe, J., Thorogood, C., 2009. The role of the midwife in Australia: views of women and midwives. Midwifery 25 (6), 673-681. 
Lamberton, J., Mahlmeister, L., 2010. Conducting root cause analysis with nursing students: best practice in nursing education. Journal of Nursing Education 49 (8), 444-448.

Lange, G., Kennedy, H. P., 2006. Student perceptions of ideal and actual midwifery practice. Journal of Midwifery \& Women's Health 51, 71-77.

doi:10.1016/j.jmwh.2005.10.003

Mitchell, M., Henderson, A., Groves, M., Nultey, D., 2009. The objective structured clinical examination (OSCE): Optimising its value in the undergraduate nursing curriculum. Nurse Education Today 29, 398-404.

Mueller, J., 2005. The authentic assessment toolbox: enhancing student learning through online faculty development. Journal of Online Learning and Teaching 1 (1), 1-7.

Newton, J.M., Billett, S., Jolly, B., Ockerby, C.M., 2009. Lost in translation: barriers to learning in health professional clinical education. Learning in Health and Social Care 8, 315-327.

Nursing and Midwifery Council, 2010. Standards for pre-registration nursing education. London, Available from (http://standards.nmcuk.org/PreRegNursing/statutory/Standards/Pages/Standards.aspx).

Payne, J., 2008.Sector skills councils and employer engagement: delivering the employer-led skills agenda in England, Journal of Education and Work 21 (2), 93-113.

Pearson, A., 2005. Minimising errors in health care: focussing on the 'root cause' rather than on the individual. International Journal of Nursing Practice 11 (4), 141.

Skirton, H., Stephen, N., Dorris, F., Cooper, M., Avis, M., Fraser, D. M., 2012. Preparedness of newly qualified midwives to deliver clinical care: an evaluation of pre-registration midwifery education through an analysis of key events, Midwifery, 28, 660-666.

Spouse, J., 2002. Take your partners for education, Nurse Education Today 22 (8), 605-607.

Tiwari, A., Lam, D., Yuen, K.H., Chan, R., Fung, T., Chan, S., 2005. Student learning in clinical nursing education: perceptions of the relationship between assessment and learning. Nurse Education Today 25 (4), 299-308. 
van der Vleuten, C., 1996. The assessment of professional competence:

developments, research and practical implications. Advances in Health Sciences Education. 1 (1), 41-67.

Woodley, C. \& Johnston, S., (2010) Engaging industry in assessment in International Conference on Work Integrated Learning: University-Industry Collaboration for Real Life Learning Conference, The Hong Kong Polytechnic University, pp. 1-12. ISSN 2153-1668. 